\title{
Cervicovaginal fluid cytokines as predictive markers of preterm birth in symptomatic women
}

\author{
Sunwha Park, MD¹, Young-Ah You, PhD², Hayoung Yun, MD1', Suk-Joo Choi, MD, PhD², \\ Han-Sung Hwang, MD, PhD ${ }^{4}$ Sae-Kyung Choi, MD, PhD ${ }^{5}$, Seung Mi Lee, MD, PhD ${ }^{6}$, Young Ju Kim, MD, PhD ${ }^{1,2}$

\begin{abstract}
${ }^{1}$ Department of Obstetrics and Gynecology, Ewha Womans University Mokdong Hospital; ${ }^{2}$ Ewha Medical Research Institute, College of Medicine, Ewha Womans University; Department of Obstetrics and Gynecology, ${ }^{3}$ Samsung Medical Center, Sungkyunkwan University School of Medicine,

${ }^{4}$ Konkuk University Medical Center, Konkuk University School of Medicine, ${ }^{5}$ College of Medicine, The Catholic University of Korea, ${ }^{6}$ Seoul National University College of Medicine, Seoul, Korea
\end{abstract}

\section{Objective}

Here, we investigated whether cytokines in the cervicovaginal fluid (CVF) can be predictive markers of preterm birth (PTB).

\section{Methods}

A multi-center prospective cohort study was conducted on 59 singleton pregnant women hospitalized for preterm labor (PTL) and/or preterm premature rupture of membranes (pPROM) between 22 weeks and 36 weeks 6 days of gestation from 2014 to 2015. The levels of 13 inflammatory cytokines (macrophage inflammatory protein [MIP]1a, MIP-1 $\beta$, tumor necrosis factor [TNF]-a, interleukin [IL]-1 $\beta$, IL-6, IL-8, IL-17a, granulocyte colony stimulating factor [G-CSF], IL-7, IL-4, IL-5, IL-10, and IL-13) were measured using a multiplex bead-based immunoassay and that of fetal fibronectin (fFN) was measured using enzyme-linked immunosorbent assay (ELISA). Statistical analyses were performed using Student's $t$-test, Mann-Whitney $U$ test, Pearson's correlation, and receiver operating characteristic (ROC) curve analysis in SPSS version 20.0.

\section{Results}

Among the 13 cytokines assessed, the levels of 3 cytokines (MIP-1a, IL-6, and IL-7) were negatively correlated with gestational age at delivery $(P=0.028, P=0.002$, and $P=0.018$, respectively). Sensitivities of MIP-1a, IL- 6 , and IL-17a were $70 \%, 80 \%$, and $75 \%$, respectively, and their specificities were $57 \%, 65 \%$, and $69 \%$, respectively. The sensitivity and specificity of fFN were $33 \%$ and $95 \%$, respectively.

\section{Conclusion}

In symptomatic women diagnosed with PTL and/or pPROM, cytokines from cervicovaginal fluid, especially IL-6 and IL$17 a$, could be better predictive markers of PTB than fFN.

Keywords: Cytokines; Interleukin-6; Interleukin-17A; Biomarkers; Preterm birth

\section{Introduction}

Preterm birth (PTB), defined as birth before 37 weeks of gestation, is a major cause of neonatal morbidity and mortality $[1,2]$. Over the past decade, the prevalence of preterm births has steadily increased worldwide. Morbidity and mortality of infants born before 34 weeks of gestation are more than those of infants born after 34 weeks. Therefore, antenatal steroid administration is recommended for patients with preterm labor (PTL) and preterm premature rupture of membranes (pPROM). However, prediction methods and therapies
Received: 2019.07.26. Revised: 2020.03.22. Accepted: 2020.04.15. Corresponding author: Young Ju Kim, MD, PhD

Department of Obstetrics and Gynecology and Ewha Medical Research Institute, College of Medicine, Ewha Womans University, 1071 Anyangcheon-ro, Yangcheon-gu, Seoul 07985, Korea E-mail: kkyj@ewha.ac.kr

https://orcid.org/0000-0002-3153-3008

Articles published in Obstet Gynecol Sci are open-access, distributed under the terms of the Creative Commons Attribution Non-Commercial License (http://creativecommons. org/licenses/by-nc/3.0/) which permits unrestricted non-commercial use, distribution, and reproduction in any medium, provided the original work is properly cited.

Copyright $\odot 2020$ Korean Society of Obstetrics and Gynecology 


\section{Obstetrics \& Gynecology Science}

Vol. 63, No. 4, 2020

for the same are not well studied.

PTB can be classified into two categories: spontaneous and iatrogenic. Spontaneous PTB accounts for up to $75 \%$ of all PTBs [3]. About $45 \%$ of PTBs are caused by PTL with intact membranes, while $30 \%$ are caused by the pre-labor rupture of fetal membranes. Causes of spontaneous PTB include activation of inflammatory reactions in the gestational tissues and secretion of inflammatory cytokines as an immune response to ascending infection of the genital tract and abnormal vaginal microorganisms [4-7].

Many studies aimed at predicting PTB have been conducted. Commonly used screening tests include risk scoring, cervical length measurement, and detection of biochemical markers. Risk scoring involves quantification of risk factors for spontaneous PTB and/or pPROM, including PTB history, cervical conization history, low socioeconomic status, low body mass index, smoking, drug use, anxiety, multifetal gestation, gestational diabetes, and gestational hypertension [6-9]. Tests for fetal fibronectin (fFN) and phosphorylated insulin-like growth factor binding protein-1 (IGFBP1) are now commercially available $[10,11]$. The level of fFN in cervicovaginal fluid (CVF), leaked due to the disruption of maternal choriodecidual tissues and through matrix remodeling, was used as a diagnostic marker for predicting PTB using a noninvasive method. Lockwood et al. described the clinical utility of fFN to predict spontaneous PTB in symptomatic women with high sensitivity (81.7\%) and specificity $(82.5 \%)$, based on a fFN threshold concentration of $\geq 50 \mathrm{ng} / \mathrm{mL}[3,8]$. However, its specificity and sensitivity were confounded by unprotected vaginal intercourse, digital examination, bleeding, or contamination with amniotic fluid $[1,12]$. Cervical length measurement using transvaginal sonograms in patients with PTL and PPROM have also been used to predict PTB; however, it requires a skilled ultrasonographer and shows limited correlation with CVF [13-15].

Increased levels of inflammatory cytokines in CVF signify intra-amniotic infection that causes PTB [16]. Several inflammatory cytokines, including interleukin (IL)-1, -2, -4, -6, -8, $-10,-12$ and -17 , tumor necrosis factor-alpha (TNF-a), interferon gamma (INF- $\gamma)$, regulated on activation, normal T cell expressed and secreted (RANTES), and C-reactive protein (CRP), have been detected in the CVF, amniotic fluid, and blood of asymptomatic and symptomatic pregnant women $[3,4,17,18]$. IL-6 and matrix metalloproteinase-8 (MMP-8) levels in the amniotic fluid were significantly correlated with
pPROM $[19,20]$. We also found that the levels of cytokines such as IL-1b, IL-6, IL-7, IL-7a, and TNF-a were significantly increased in the amniotic fluid of patients with cervical insufficiency [16]. Thereafter, the objective of our study was to determine whether inflammatory cytokines could be measured using non-invasive methods. Recent studies have shown that IL-6, IL-8, macrophage inflammatory protein (MIP)-1a, and MIP-1 $\beta$ levels in the CVF of patients with PPROM were correlated with those in the amniotic fluid [21]. IL-1, IL$6, I L-8$, and TNF-a levels were also elevated in patients with intact membranes in PTL [22]. There have also been studies in which IL-6 was shown to be a useful marker for predicting preterm delivery.

In the preset study, we expected that the levels of inflammatory cytokines in the CVF would be elevated in patients with PTL and PPROM. We investigated whether the levels of cytokines in the CVF could be a better predictive marker of PTB than that of fFN in CVF.

\section{Materials and methods}

\section{Study population}

A multi-center (Ewha Womans University Mokdong Hospital, Samsung Medical Center, Konkuk University Hospital, Seoul St. Mary's Hospital, and Seoul Metropolitan GovernmentSeoul National University Boramae Medical Center) prospective cohort study was conducted in singleton pregnant women suffering from complications of PTL and/or pPROM between 22 weeks and 36 weeks 6 days of gestation, from 2014 to 2015. The characteristics (age, parity, and body mass index at admission) of the mother were analyzed. To diagnose PPROM, sterile speculum exam was conducted for detecting amniotic fluid pooling in vaginal cavity and nitrazine test was done. Uterine activity was assessed by cardiotocography. PTL was diagnosed in patients with regular uterine contraction and 4 or more contractions in 20 minutes, or 8 or more in 60 minutes as detected by cardiotocography. A total of 65 women with singleton pregnancies were included in this study. Patients with preeclampsia, hemolysis, elevated liver enzymes, a low platelet count (HELLP) syndrome, incompetent internal os of cervix (IIOC), and placenta previa were excluded. Out of the 59 participants, 19 were diagnosed with PPROM, and the rest with PTL (Fig. 1); no patient was suspected of clinical chorioamnionitis, defined according to 


\section{Obstetrics \& Gynecology Science}

Sunwha Park, et al. CVF cytokine for prediction of PTB

the criteria of Gibbs et al. [23], which includes the presence of fever $\left(>37.8^{\circ} \mathrm{C}\right)$ and two or more of the following associated clinical findings: uterine tenderness, malodorous vaginal discharge, maternal leukocytosis, maternal tachycardia, and fetal tachycardia. Gestational age was estimated by fetal biometry, assessed using a sonogram during the first trimester. Cervical length was measured at the time of admission by transvaginal ultrasound. Vaginal transducers were placed in the anterior fornix to examine the endocervical canal. Calipers were used to measure the length of the cervical canal from internal to external os. Women with pPROM at less than 35 weeks of gestation were treated with corticosteroids, tocolytics, and antibiotics. After 34 weeks, all patients with pPROM underwent induced delivery, when there was no labor pain, or cesarean section, if it was indicated. Those with PTL were treated with corticosteroids and tocolytics. We checked pregnancy outcome in terms of gestational age at delivery, birth weight, and Apgar score of the newborn at 1 and 5 minutes.

\section{Cervicovaginal fluid collection and laboratory study}

CVF was collected from the posterior vaginal fornix with a sterile cotton swab and stored at $-80^{\circ} \mathrm{C}$ within 30 minutes of collection, until further analysis. The levels of 13 inflam-

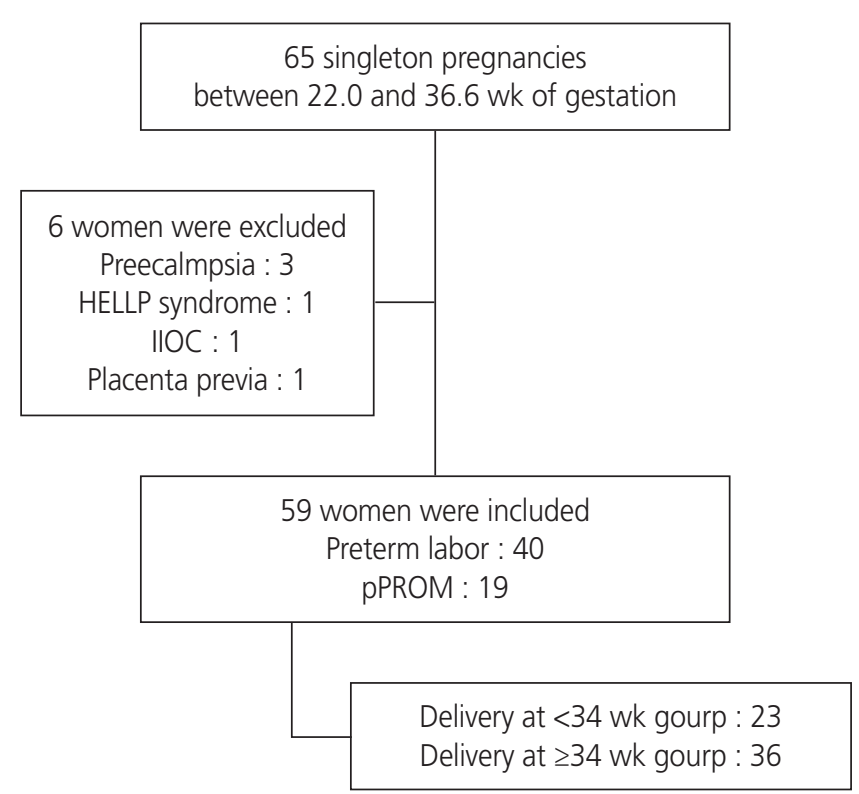

Fig. 1. Flow chart of participants in the cohort study. HELLP, hemolysis, elevated liver enzymes, and a low platelet count; IIOC, incompetent internal os of cervix. matory cytokines (MIP-1a, MIP-1 $\beta$, TNF- $\alpha$, IL-1 $\beta$, IL-6, IL-8, IL17a, granulocyte-colony stimulating factor [G-CSF], IL-7, IL4, IL-5, IL-10, and IL-13) in the CVF were measured using the Human Cytokine/Chemokine Magnetic Bead Panel (Merck Millipore, Burlington, MA, USA). The intra-assay and interassay variations of all analyses were less than $10 \%$ and $12 \%$, respectively. fFN in CVF was also sampled similarly and measured using a human fFN enzyme-linked immunosorbent assay (ELISA) kit (CUSABIO, Houston, TX, USA).

\section{Statistical analysis}

Statistical analyses were performed using the Statistical Package for Social Sciences (version 20; SPSS Inc., Chicago, IL, USA). Clinical characteristics were compared using Student's $t$-test for continuous variables and $\chi^{2}$ test for categorical variables. $P<0.05$ was considered statistically significant. The relationship between the level of cytokines and gestational age at delivery was analyzed using Pearson's correlation. The levels of cytokines were analyzed by the Mann-Whitney $U$ test and compared between preterm delivery group (delivery at $<34$ weeks) and normal controls (delivery at $\geq 34$ weeks). Receiver operating characteristic (ROC) curves of cytokine levels in early preterm birth were generated and the area under the curve (AUC) was determined.

\section{Results}

\section{Characteristics of the study population}

The demographic and clinical data of the study participants are presented in Table 1. The study group consisted of 23 pregnant women who delivered before 34 weeks of gestation and the controls $(n=36)$ delivered after 34 weeks of gestation. There was no significant difference in age, parity, body mass index, and cervical length between the two groups $(P=0.519, P=0.730, P=0.487$, and $P=0.381$, respectively). fFN in the CVF showed a significant difference between the two groups $(P=0.017)$. The study group was divided into PTL- and pPROM- subgroups. Frequency analysis was performed at the time of admission using the $\chi^{2}$ test for the diagnosis. There was no statistical difference in the distribution between the two groups, with a $P$-value of 0.77 . Gestational age at the time of diagnosis was significantly different for the two groups $(P=0.002)$. The white blood cell count, birth weight, and Apgar score of the newborns showed sig- 


\section{Obstetrics \& Gynecology Science}

Vol. 63, No. 4, 2020

nificant differences between the two groups $(P<0.001)$.

\section{Cytokine levels in the cervicovaginal fluid in the study and control groups}

Among the 13 cytokines considered for the study, 9 (MIP-

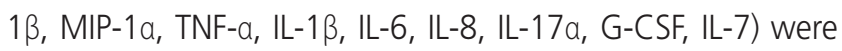
detected in the $C V F$ of the 2 groups. Fig. 2 graphically shows the correlation of these 9 cytokines with the gestational age at delivery; 4 of these (MIP-1a, MIP-1 $\beta, I L-6$, and IL-7) showed a significant negative correlation $(P=0.003, P=0.010$, $P=0.035$, and $P=0.041$, respectively). The levels of these 9 cytokines were compared between the study group and control group and are shown in Table 2. The levels of 3 cytokines (MIP-1a, IL-6, and IL-17a) were significantly higher in patients with PTL and/or pPROM who delivered before 34 weeks of gestation, compared to controls $(P=0.028, P=0.002$, and $P=0.018$, respectively). ROC curves were constructed for the 5 cytokines (MIP-1a, MIP-1 $\beta, I L-6, I L-7$, and IL-17a) showing significant differences between the two groups and AUC values and optimal concentration thresholds for predictive utility were determined. Based on these thresholds, the sensitivities and specificities for the prediction of PTB were deter- mined (Fig. 3 and Table 3). Sensitivities of MIP-1 $\beta$, MIP-1a, IL6, IL-17a, and IL-7 were 47\%, 70\%, 80\%, 75\%, and 35\%, respectively, and their specificities of were $82 \%, 57 \%, 65 \%$, $69 \%$, and $94 \%$, respectively; the areas under the ROC curves of these cytokines were $0.676,0.677,0.788,0.715$, and 0.643 , respectively. The sensitivity and specificity of CVF fFN were $33 \%$ and $95 \%$, respectively. Forty patients who were diagnosed with PTL at the time of admission were analyzed. The levels of IL- 6 and IL-7 showed significant increase in the study group with $P$-values of 0.023 and 0.040 , respectively (Supplementary Table 1). The ROC curves for these 2 cytokines were constructed and AUC values and optimal concentration thresholds for predictive utility were determined (Supplementary Table 2). Sensitivities of IL-6 and IL-7 were $83 \%$ and $83 \%$, respectively, and their specificities were $76 \%$ and $64 \%$, respectively. The sensitivity and specificity of CVF fFN were $33 \%$ and $70 \%$, respectively. Subgroup analysis of 19 patients who were diagnosed with PPROM at the time of admission compared the cytokines of PTB and control group. IL-1 $\beta$ showed a significant difference with $P$-value 0.043 (Supplementary Table 3).

Table 1. Clinical characteristics of the study population $(n=59)$

\begin{tabular}{|c|c|c|c|}
\hline Characteristics & Delivery at <34 wk $(n=23)$ & Delivery at $\geq 34$ wk $(n=36)$ & $P$-value ${ }^{\text {a) }}$ \\
\hline Maternal age (yr) & $31(23-38)$ & $32(19-46)$ & 0.519 \\
\hline Nulliparity & $6(16.7)$ & $3(13.0)$ & $0.730^{\mathrm{d})}$ \\
\hline $\mathrm{BMI}\left(\mathrm{kg} / \mathrm{m}^{2}\right)$ & $24(20-33)$ & $25(18-32)$ & 0.487 \\
\hline Fetal fibronectin (ng/mL) & $133(11-699)$ & $40(11-142)$ & $0.017^{b)}$ \\
\hline WBC (cell/mL) & $13,596(8,130-24,280)$ & $10,063(6,440-16,640)$ & $<0.001^{c)}$ \\
\hline Cervical length (mm) & $20(0-44)$ & $23(2-69)$ & 0.381 \\
\hline$<25 \mathrm{~mm}$ group & $12(57.1)$ & $18(54.5)$ & $>0.990^{\mathrm{d})}$ \\
\hline$\geq 25 \mathrm{~mm}$ group & $9(42.9)$ & $15(45.5)$ & \\
\hline \multicolumn{4}{|l|}{ Diagnosis at admission } \\
\hline PTL group & $12(52.2)$ & $28(77.8)$ & $0.077^{d)}$ \\
\hline pPROM group & $11(47.8)$ & $8(22.2)$ & \\
\hline Gestational age at admission (wk) & $28(22-33)$ & $31(20-36)$ & $0.002^{b)}$ \\
\hline Gestational age at delivery (wk) & $29(23-33)$ & $36(34-41)$ & $<0.001^{c)}$ \\
\hline Birth weight (g) & $1,323(570-2,320)$ & $2,640(780-3,740)$ & $<0.001^{c)}$ \\
\hline Apgar score at $1 \mathrm{~min}$ & $6(0-10)$ & $8(4-10)$ & $<0.001^{c)}$ \\
\hline Apgar score at $5 \mathrm{~min}$ & $7(0-10)$ & $9(8-10)$ & $<0.001^{\mathrm{c}}$ \\
\hline
\end{tabular}

Data are expressed as median (range) for continuous variables and number (\%) for categorical variables.

BMI, body mass index; WBC, white blood cell; PTL, preterm labor; pPROM, preterm premature rupture of membranes.

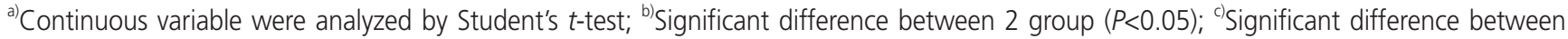
2 group $(P<0.001) ;{ }^{d}$ Categorical variable was analyzed by $\chi^{2}$ test. 


\section{Obstetrics \& Gynecology Science}

Sunwha Park, et al. CVF cytokine for prediction of PTB
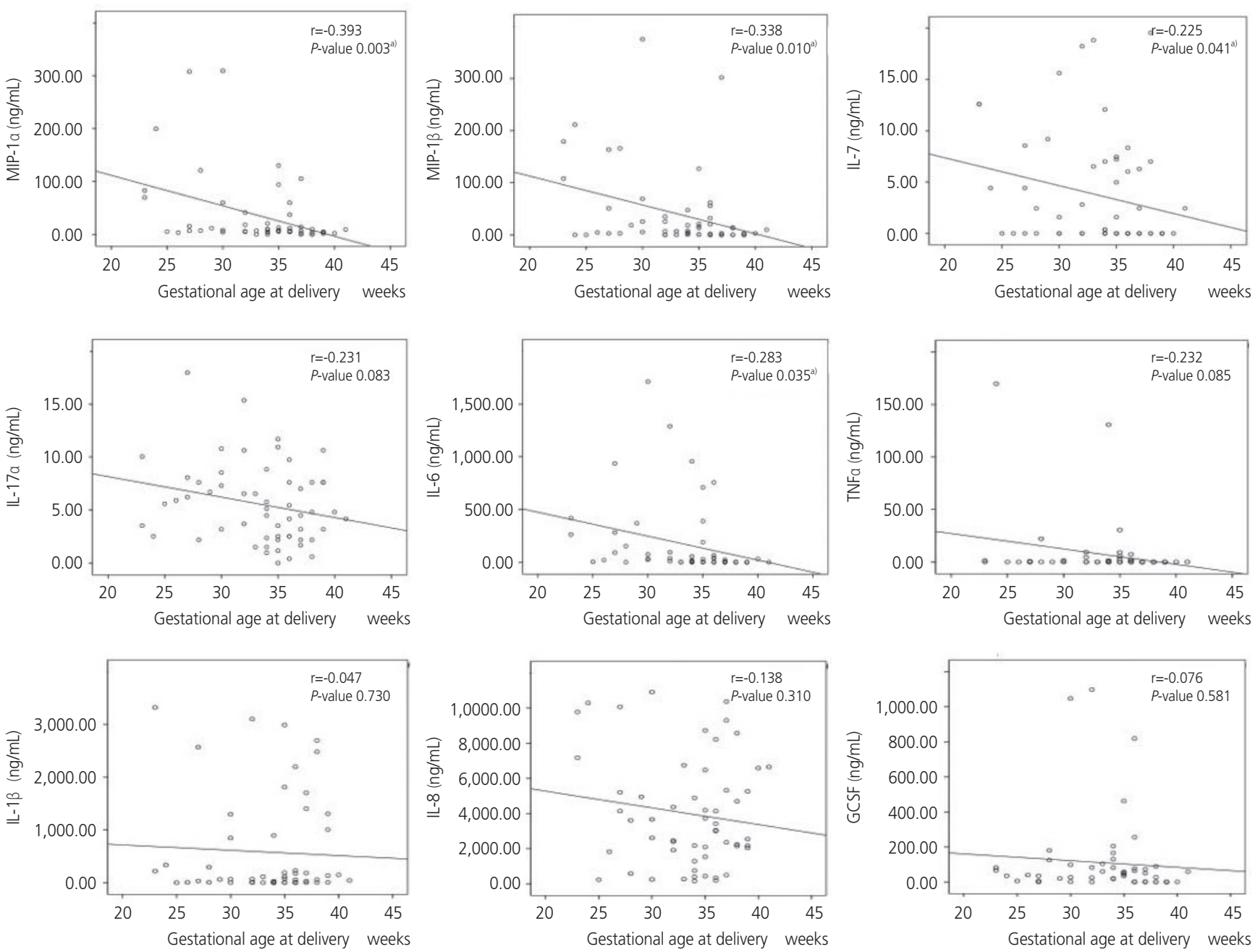

Fig. 2. The relationship between cytokine level and gestational age at delivery. Using Pearson correlation. MIP, macrophage inflammatory

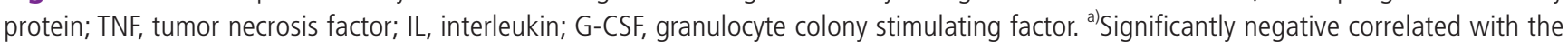
gestational age at delivery $(P<0.05)$.

Table 2. Cervicovaginal fluid cytokine levels in patients in the study group and control group

\begin{tabular}{lccc}
\hline Cytokine & Delivery at $<\mathbf{3 4} \mathbf{~ w k}(\mathbf{n}=\mathbf{2 3})$ & Delivery at $\mathbf{3} \mathbf{3 4} \mathbf{w k}(\mathbf{n = 3 6 )}$ & $\boldsymbol{P}_{\text {-value }} \mathbf{b}^{\mathbf{b}}$ \\
\hline MIP-1 $\beta$ & $18.56(0-375.00)$ & $2.89(0-301.56)$ & 0.067 \\
MIP-1a & $11.62(0-309.47)$ & $5.73(0-130.48)$ & $0.028^{\text {a) }}$ \\
TNF- $a$ & $0(0-169.67)$ & $0(0-130.66)$ & 0.661 \\
IL-1 $\beta$ & $65.35(0-3,321.48)$ & $67.08(0-2,990.27)$ & 0.738 \\
IL-6 & $83.27(0-1,712.41)$ & $1.44(0-956.15)$ & $0.002^{\text {a) }}$ \\
IL-8 & $3,663.22(234.78-10,911.85)$ & $3,007.72(154.79-10,365.90)$ & 0.472 \\
IL-17a & $6.54(1.51-17.97)$ & $4.17(0-11.69)$ & $0.018^{\text {a) }}$ \\
G-CSF & $38.80(0-1,097.48)$ & $38.74(0-818.30)$ & 0.225 \\
IL-7 & $2.81(0-18.83)$ & $0(0-19.55)$ & 0.064 \\
\hline
\end{tabular}

Data are expressed as the median (range) (pg/mL).

MIP, macrophage inflammatory protein; TNF, tumor necrosis factor; IL, interleukin; G-CSF, granulocyte colony stimulating factor.

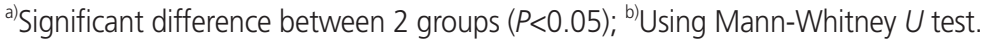




\title{
Obstetrics \& Gynecology Science
}

\author{
Vol. 63, No. 4, 2020
}

\section{Discussion}

Our study showed that elevated levels of multiple cytokines (MIP-1a, MIP-1 $\beta, I L-6, I L-7$, and IL-17a) in the CVF were associated with PTB. Among these, IL-6 and IL-17a showed better sensitivity than the more commonly used marker fFN. This indicated that IL-6 and IL-17a can be used as predictive markers for PTB.

Fetal fibronectin, involved in maintaining the integrity of the fetal chorion and maternal decidua, predicts spontaneous PTB when detected in CVF between 22 and 34 weeks of gestation. Meta-analysis of Leitich et al. [24], found the sensitivity and specificity of fFN in predicting PTB in mothers with PTL to be $63 \%$ and $86 \%$, respectively. In our study,

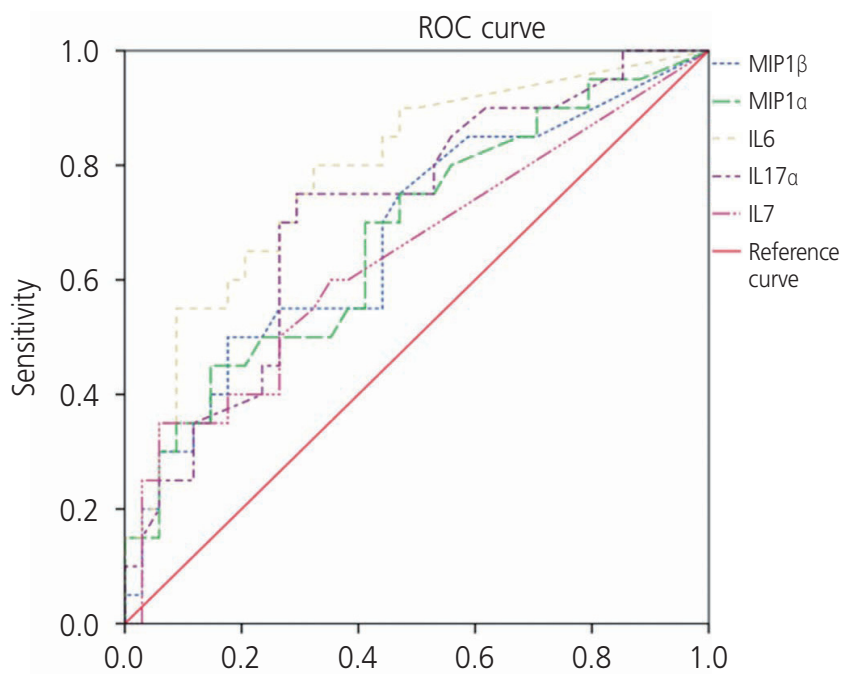

Fig. 3. ROC curves of 5 cytokines in the prediction of early preterm birth (delivery at $<34$ weeks). ROC, receiver operating characteristic; MIP, macrophage inflammatory protein; TNF, tumor necrosis factor; IL, interleukin; G-CSF, granulocyte colony stimulating factor. however, fFN showed 33\% sensitivity of and 95\% specificity as a predictor of PTB. As shown in Table 3, the sensitivities of IL- 6 and IL-17a were higher than those of fFN by $80 \%$ and $75 \%$, respectively. The AUC of fFN was 0.662 , while those of IL- 6 and IL-17a were 0.788 and 0.715 , respectively. The results for fFN may be confounded by unprotected vaginal intercourse, digital examination, bleeding, or contamination with amniotic fluid $[1,12]$. We did not consider the amniotic fluid contamination of CVF as a confounding factor and believe that it affected the outcome for pPROM patients. Therefore, in the subgroup analysis, the fFN and cytokine levels of the PTL patients, but not of the PPROM patients, were compared. In subgroup analysis, the sensitivity of IL- 6 and IL-7 both were $83 \%$, which was higher than the 33\% sensitivity of fFN.

Several protein mediators and cytokines have been studied in the amniotic fluid, blood, urine, and CVF $[1,25,26]$. Studies considering the association of elevated inflammatory cytokines with chorioamnionitis and PTL were initiated in the amniotic fluid [19]. However, since amniocentesis itself is an invasive method, many studies sought to measure the same non-invasively in the blood, urine, and CVF. The composition of human CVF reflects the local biochemical environment of the gestational tissues. Therefore, CVF proteins, such as fFN, IGFBP1, defensins, lactoferrin, sialidase, granulocyte elastase, human chorionic gonadotropin, IL-1ß, IL-6, IL-8, IL-18, IL-1 receptor antagonists, and TNF have been utilized to predict PTB [27-32]. Particularly, LL-6 is strongly associated with intraamniotic inflammation and microbe-associated intra-amniotic inflammation; hence, measurement of IL-6 in CVF can be used as an easy, noninvasive, rapid method for point-of-care assessment $[33,34]$. IL-6 induces T-lymphocytes to synthesize C-reactive protein and to promote the differentiation of Bcells. It is a pro-inflammatory cytokine seen widely in de-

Table 3. Receiver operating characteristic curve analysis

\begin{tabular}{|c|c|c|c|c|c|c|}
\hline Cytokine & AUC & $95 \% \mathrm{Cl}$ & $P$-value & Cut-off & Sensitivity & Specificity \\
\hline MIP-1 $\beta$ & 0.676 & $0.525-0.828$ & 0.032 & 17.51 & 47 & 82 \\
\hline MIP-1a & 0.677 & $0.527-0.828$ & 0.031 & 6.46 & 70 & 57 \\
\hline IL-6 & 0.788 & $0.661-0.915$ & 0.000 & 23.46 & 80 & 65 \\
\hline$\| \mathrm{L}-17 \mathrm{a}$ & 0.715 & $0.574-0.857$ & 0.009 & 5.53 & 75 & 69 \\
\hline IL-7 & 0.643 & $0.485-0.802$ & 0.081 & 0.98 & 35 & 94 \\
\hline Fibronectin & 0.662 & $0.494-0.830$ & 0.073 & 74.50 & 33 & 95 \\
\hline
\end{tabular}

AUC, area under a receiver operating characteristic curve; $\mathrm{Cl}$, confidence interval; MIP, macrophage inflammatory protein; IL, interleukin. 


\section{Obstetrics \& Gynecology Science}

Sunwha Park, et al. CVF cytokine for prediction of PTB

cidual tissue, placenta, fetal membrane, and amniotic fluid, and regulates immune adaptation to allow the pregnancy to progress. Preterm labor and pPROM are thought be because of the inflammatory condition caused by infection. Our study has showed that IL-6 is superior to conventional fFN assays. $\mathrm{IL}-17 \mathrm{a}$ as a protective cytokine in host defense against bacterial and fungal infections, was shown to be associated with intra-amniotic inflammation [35]. No study has analyzed IL17 in the CVF; however, IL-17a was significantly elevated in the amniotic fluid of patients with cervical insufficiency [16]. MIP-1 $a$ and MIP-1 $\beta$ are produced in the macrophages in response to infection and inflammation. They subsequently activate human granulocytes and the level of MIP-1a in the CVF is associated with amniotic fluid infection $[21,36,37]$. MIP-1a has been studied in the CVF of patients with pPROM, but not PTL. In this study, we found that elevation of the MIP-1a level in the CVF was associated with PTL. IL-7 is a cytokine that can stimulate IL-17 production by cells involved in both innate and adaptive immunity. Elevated serum IL-7 is also associated with PTL [38].

Although our sample size was small, the strength of this study is that it was conducted as a multi-center prospective study in 5 centers in Korea. This study directly compared cytokines and fFN in the CVF from the same cohort of patients. When selecting a patient group, the ones with multiple gestation, gestational diabetes, and gestational hypertension were excluded. However, factors such as cervical conization history, socio-economic status, pre-pregnancy body mass index, smoking, drug use, and anxiety that could be confounding factors could not be excluded. The gestational age at diagnosis is also a confounding factor that may affect the gestational age at delivery, but no analysis has been done to correct this.

In conclusion, CVF cytokines, especially IL-6, IL-17a, could be useful predictive markers of PTB in patients with PTL and/ or pPROM; however, studies with larger cohort will be required for validation of these findings.

\section{Acknowledgements}

This research was supported by the Ministry of Health and Welfare of the Republic of Korea (Grant Number: HI18C0378) through the Korea Health Industry Development Institute.
We would like to thank Editage (www.editage.co.kr) for English language editing.

\section{Conflict of interest}

No potential conflict of interest relevant to this article was reported.

\section{Ethical approval}

This study was approved by the Institutional Review Board Committee of Ewha Womans University Mokdong Hospital (certificate No. EUMC 2014-06-010).

\section{Patient consent}

The patients provided written informed consent for the publication and the use of their images.

\section{Supplementary materials}

Supplementary Tables associated with this article can be found online at https://doi.org/10.5468/ogs.19131.

\section{References}

1. Heng YJ, Liong S, Permezel M, Rice GE, Di Quinzio MK, Georgiou HM. Human cervicovaginal fluid biomarkers to predict term and preterm labor. Front Physiol 2015;6:151.

2. Yoo JY, You YA, Kwon EJ, Park MH, Shim S, Kim YJ. Differential expression and methylation of integrin subunit alpha 11 and thrombospondin in the amnion of preterm birth. Obstet Gynecol Sci 2018;61:565-74.

3. Chan RL. Biochemical markers of spontaneous preterm birth in asymptomatic women. BioMed Res Int 2014;2014:164081.

4. Amabebe E, Chapman DR, Stern VL, Stafford G, Anumba DO. Mid-gestational changes in cervicovaginal fluid cytokine levels in asymptomatic pregnant women are 


\section{Obstetrics \& Gynecology Science}

Vol. 63, No. 4, 2020

predictive markers of inflammation-associated spontaneous preterm birth. J Reprod Immunol 2018;126:1-10.

5. Jefferson KK. The bacterial etiology of preterm birth. Adv Appl Microbiol 2012;80:1-22.

6. Dekker GA, Lee SY, North RA, McCowan LM, Simpson NA, Roberts CT. Risk factors for preterm birth in an international prospective cohort of nulliparous women. PLoS One 2012;7:e39154.

7. Son KA, Kim M, Kim YM, Kim SH, Choi SJ, Oh SY, et al. Prevalence of vaginal microorganisms among pregnant women according to trimester and association with preterm birth. Obstet Gynecol Sci 2018;61:38-47.

8. Kim YJ, Lee BE, Park HS, Kang JG, Kim JO, Ha EH. Risk factors for preterm birth in Korea: a multicenter prospective study. Gynecol Obstet Invest 2005;60:206-12.

9. Baer RJ, McLemore MR, Adler N, Oltman SP, Chambers $B D$, Kuppermann $M$, et al. Pre-pregnancy or first-trimester risk scoring to identify women at high risk of preterm birth. Eur J Obstet Gynecol Reprod Biol 2018;231:23540.

10. Conde-Agudelo A, Papageorghiou AT, Kennedy SH, Villar J. Novel biomarkers for the prediction of the spontaneous preterm birth phenotype: a systematic review and meta-analysis. BJOG 2011;118:1042-54.

11. Paternoster DM, Muresan D, Vitulo A, Serena A, Battagliarin $\mathrm{G}$, Dell'avanzo $M$, et al. Cervical phIGFBP-1 in the evaluation of the risk of preterm delivery. Acta Obstet Gynecol Scand 2007;86:151-5.

12. Liong S, Di Quinzio MK, Fleming G, Permezel M, Rice $\mathrm{GE}$, Georgiou HM. New biomarkers for the prediction of spontaneous preterm labour in symptomatic pregnant women: a comparison with fetal fibronectin. BJOG 2015;122:370-9.

13. Son M, Miller ES. Predicting preterm birth: cervical length and fetal fibronectin. Semin Perinatol 2017:41:445-51.

14. Chandiramani M, Seed PT, Orsi NM, Ekbote UV, Bennett $P R$, Shennan $A H$, et al. Limited relationship between cervico-vaginal fluid cytokine profiles and cervical shortening in women at high risk of spontaneous preterm birth. PLoS One 2012;7:e52412.

15. DeFranco EA, Lewis DF, Odibo AO. Improving the screening accuracy for preterm labor: is the combination of fetal fibronectin and cervical length in symptomatic patients a useful predictor of preterm birth? A system- atic review. Am J Obstet Gynecol 2013;208:233.e1-6.

16. Son GH, You YA, Kwon EJ, Lee KY, Kim YJ. Comparative analysis of midtrimester amniotic fluid cytokine levels to predict spontaneous very pre-term birth in patients with cervical insufficiency. Am J Reprod Immunol 2016;75:155-61.

17. Gulati S, Agrawal S, Raghunandan C, Bhattacharya J, Saili A, Agarwal $S$, et al. Maternal serum interleukin-6 and its association with clinicopathological infectious morbidity in preterm premature rupture of membranes: a prospective cohort study. J Matern Fetal Neonatal Med 2012;25:1428-32.

18. Curry AE, Vogel I, Skogstrand K, Drews C, Schendel DE, Flanders WD, et al. Maternal plasma cytokines in earlyand mid-gestation of normal human pregnancy and their association with maternal factors. J Reprod Immunol 2008;77:152-60.

19. Chaemsaithong P, Romero R, Docheva N, Chaiyasit N, Bhatti G, Pacora P, et al. Comparison of rapid MMP8 and interleukin-6 point-of-care tests to identify intraamniotic inflammation/infection and impending preterm delivery in patients with preterm labor and intact membranes. J Matern Fetal Neonatal Med 2018;31:228-44.

20. Musilova I, Bestvina T, Hudeckova M, Michalec I, Cobo $T$, Jacobsson B, et al. Vaginal fluid IL-6 concentrations as a point-of-care test is of value in women with preterm PROM. Am J Obstet Gynecol. Forthcoming 2016.

21. Lee SM, Park KH, Jung EY, Kook SY, Park H, Jeon SJ. Inflammatory proteins in maternal plasma, cervicovaginal and amniotic fluids as predictors of intra-amniotic infection in preterm premature rupture of membranes. PLoS One 2018;13:e0200311.

22. Coleman MA, Keelan JA, McCowan LM, Townend KM, Mitchell MD. Predicting preterm delivery: comparison of cervicovaginal interleukin (IL)-1 beta, IL-6 and IL-8 with fetal fibronectin and cervical dilatation. Eur J Obstet Gynecol Reprod Biol 2001;95:154-8.

23. Gibbs RS, Blanco JD, St Clair PJ, Castaneda YS. Quantitative bacteriology of amniotic fluid from women with clinical intraamniotic infection at term. J Infect Dis 1982;145:1-8.

24. Leitich $\mathrm{H}$, Kaider $\mathrm{A}$. Fetal fibronectin--how useful is it in the prediction of preterm birth? BJOG 2003;110 Suppl 20:66-70.

25. Goldenberg RL, lams JD, Mercer BM, Meis PJ, Moawad 


\section{Obstetrics \& Gynecology Science}

Sunwha Park, et al. CVF cytokine for prediction of PTB

A, Das A, et al. The Preterm Prediction Study: toward a multiple-marker test for spontaneous preterm birth. Am J Obstet Gynecol 2001;185:643-51.

26. Heng YJ, Di Quinzio MK, Permezel M, Rice GE, Georgiou HM. Interleukin-1 receptor antagonist in human cervicovaginal fluid in term pregnancy and labor. Am J Obstet Gynecol 2008;199:656.e1-7.

27. Kekki M, Kurki T, Kärkkäinen T, Hiilesmaa V, Paavonen J, Rutanen EM. Insulin-like growth factor-binding protein-1 in cervical secretion as a predictor of preterm delivery. Acta Obstet Gynecol Scand 2001;80:546-51.

28. Lockwood CJ, Senyei AE, Dische MR, Casal D, Shah KD, Thung $S N$, et al. Fetal fibronectin in cervical and vaginal secretions as a predictor of preterm delivery. N Engl J Med 1991;325:669-74.

29. Rizzo G, Capponi A, Rinaldo D, Tedeschi D, Arduini D, Romanini C. Interleukin-6 concentrations in cervical secretions identify microbial invasion of the amniotic cavity in patients with preterm labor and intact membranes. Am J Obstet Gynecol 1996;175:812-7.

30. Jacobsson B, Holst RM, Mattsby-Baltzer I, Nikolaitchouk $\mathrm{N}$, Wennerholm UB, Hagberg H. Interleukin-18 in cervical mucus and amniotic fluid: relationship to microbial invasion of the amniotic fluid, intra-amniotic inflammation and preterm delivery. BJOG 2003;110:598-603.

31. Tanaka Y, Narahara H, Takai N, Yoshimatsu J, Anai T, Miyakawa I. Interleukin-1 $\beta$ and interleukin-8 in cervicovaginal fluid during pregnancy. Am J Obstet Gynecol 1998;179:644-9.

32. Sanchez-Ramos L, Mentel C, Bertholf R, Kaunitz AM,
Delke I, Loge C. Human chorionic gonadotropin in cervicovaginal secretions as a predictor of preterm delivery. Int J Gynaecol Obstet 2003;83:151-7.

33. Kacerovsky M, Musilova I, Jacobsson B, Drahosova M, Hornychova $\mathrm{H}$, Janku P, et al. Cervical fluid IL-6 and IL-8 levels in pregnancies complicated by preterm prelabor rupture of membranes. J Matern Fetal Neonatal Med 2015;28:134-40.

34. Ashford K, Chavan NR, Wiggins AT, Sayre MM, McCubbin A, Critchfield AS, et al. Comparison of serum and cervical cytokine levels throughout pregnancy between preterm and term births. AJP Rep 2018;8:e113-20.

35. Kiefer DG, Peltier MR, Keeler SM, Rust O, Ananth CV, Vintzileos AM, et al. Efficacy of midtrimester short cervix interventions is conditional on intraamniotic inflammation. Am J Obstet Gynecol 2016;214:276.e1-6.

36. Romero R, Gomez R, Galasso M, Munoz H, Acosta L, Yoon $\mathrm{BH}$, et al. Macrophage inflammatory protein-1 alpha in term and preterm parturition: effect of microbial invasion of the amniotic cavity. Am J Reprod Immunol 1994;32:108-13.

37. Lee SM, Park KH, Jung EY, Cho SH, Ryu A. Prediction of spontaneous preterm birth in women with cervical insufficiency: comprehensive analysis of multiple proteins in amniotic fluid. J Obstet Gynaecol Res 2016;42:776-83.

38. Herrera-Muñoz A, Fernández-Alonso AM, Fischer-Suárez N, Chedraui P, Pérez-López FR. Maternal serum cytokine levels in pregnancies complicated with threatened preterm labour. Gynecol Endocrinol 2017;33:408-12. 